\title{
Dos concepciones de la razón: una confrontación de Thérèse Philosophe con la filosofía moral kantiana
}

\author{
Daniel Rudy HILLER \\ École Normale Supérieure \\ Université Sorbonne Nouvelle-Paris III
}

\begin{abstract}
Saber si la razón es capaz o no de tener un influjo directo sobre la voluntad y, por lo tanto, sobre la libertad, es una de las cuestiones más debatidas en el pensamiento del siglo XVIII. De su resolución en uno u otro sentido depende conocer si la felicidad o la moralidad constituye el fin último de la existencia humana. En este artículo se aborda este debate tomando como hilo conductor la confrontación de un texto representativo de la literatura libertina, Thérèse Philosophe, con la filosofía moral kantiana.
\end{abstract}

PALABRAS ClaVE: Immanuel Kant, Thérèse Philosophe, libertad, voluntad, moralidad, sexualidad, felicidad.

Knowing if reason is capable or not of having a direct influence on free-will, and consequently, on freedom, is one of the most discussed subjects in XVIII thought. Depending on the answer, happiness or morality would be considered as the true goal of human existence. This article discusses this debate by putting face to face a representative novel of libertine literature, Thérèse Philosophe, with Kant's moral philosophy.

KeY words: Immanuel Kant, Thérèse Philosophe, freedom, free-will, morality, sexuality, happiness.

Si nos dejamos guiar por la idea que sus coetáneos y sus biógrafos nos han transmitido de él, resulta difícil imaginar a Immanuel Kant leyendo una novela libertina, no digamos ya una novela pornográfica como es con frecuencia calificada Thérèse Philosophe, obra atribuida al marqués Boyer d'Argens y publicada en 1748. No es que Kant detestara las novelas (se sabe, de hecho, que leía con entusiasmo La nouvelle Heloïse de Rousseau), pero lo cierto es que entre su rígida disciplina y la relajada licenciosidad de los personajes libertinos existe una incompatibilidad patente. Todavía más, ya que las novelas de corte amoroso, lo que Kant denominaba los "escritos sentimentales", le inspiraban suma desconfianza en la medida en que engendraban en 
los hombres "vanos deseos y ansias de una perfección inasequible" que redundaban en el descuido de sus obligaciones inmediatas. ${ }^{1}$ En una palabra, parecería haber pocas cosas tan contrapuestas, y por ello mismo tan incomparables, como la personalidad de Kant y el espíritu de su producción filosófica, y el tono (no pensemos ya en el contenido) de Thérèse Philosophe.

Tal sería, pues, la situación, si dicha novela, especie de Bildungsroman sexual cuya protagonista es una mujer francesa de mediados del siglo XVIII, se confinara a ser una mera relación de escenas en las que se da libre juego a la lujuria. Thérèse Philosophe, sin embargo, es mucho más que eso, ya que su propósito no reside únicamente en escandalizar al público o bien en entretenerlo en virtud de una sucesión de anécdotas grivoises, sino, designio de mucho mayor alcance, en reivindicar el derecho tanto a la existencia como a la satisfacción de los instintos sexuales. Con todo, la lógica de la reivindicación exige la existencia de un adversario respecto del cual otro vaya a ser reivindicado. El autor de Thérèse es consciente de ello, y de ahí el origen de su estrategia: proveer a sus contemporáneos de un arsenal de argumentos filosóficos cuyo objetivo fuera refutar las posiciones que la tradición cristiana sostenía contra la sexualidad.

Ahora bien, en términos filosóficos sí resulta factible establecer una relación, aunque sea de antagonismo, entre Thérèse Philosophe y la filosofía moral kantiana. Es posible, casi seguro, que Kant jamás leyera una novela libertina. A lo sumo puede proponerse, a manera de sugerencia, un pasaje del prólogo a la Fundamentación, en donde Kant asevera que las costumbres quedan expuestas a toda suerte de perversidades, mientras el principio supremo de la moralidad no haya sido explicitado. ${ }^{2}$ No obstante, aventurarse a afirmar si Kant hacía referencia aquí, entre otras cosas, a la filosofía libertina, es ir demasiado lejos.

Y sin embargo, al comparar las tesis éticas defendidas por Thérèse y por Kant, uno tiene la impresión de que las de este último representan una réplica directa a las primeras, tal y como si Kant las hubiera estudiado y se hubiera decidido a rebatirlas. Existe entre ambas, en efecto, una suerte de relación especular: allí donde Thérèse niega la libertad de la voluntad, Kant la afirma; donde la primera pone a la felicidad como el fin supremo de la vida, Kant coloca a la moralidad. Investigar si se trató de una reacción consciente o no, es, por lo demás, inútil para el propósito de este texto. Es necesario aclarar que no nos hallamos en el terreno de lo biográfico (por más que sea preciso echar mano de él de vez en cuando), sino de la historia de las ideas, y en este sentido se abre la posibilidad de interpretar la filosofía moral kantiana como una refutación de las premisas básicas de la filosofía libertina y de sus consecuentes implicaciones. En todo caso, en este escrito me interesa reconstruir los razonamientos filosóficos de ambas partes, con la intención de desprender de ellos sus

\footnotetext{
${ }^{1}$ Para la opinión de Kant sobre las novelas y los "escritos sentimentales", cf. Crítica de la razón práctica. Trad. Roberto Rodríguez Aramayo. Madrid, Alianza, 2000, A 276 (325).

${ }^{2} C f$. Immanuel Kant, Fundamentación para una metafisica de las costumbres. Trad. Roberto Rodríguez Aramayo, Madrid, Alianza, 2012, A X (p. 72).
} 
consecuencias en el ámbito de la historia de las ideas, así como con la intención de confrontar las distintas concepciones del ser humano que fundamentan cada una de estas dos filosofías morales.

\section{II}

Como sugerí en el primer apartado, Thérèse Philosophe puede ser considerada como una novela motivada por una razón, a saber: reivindicar el lugar del placer sexual en la vida del hombre para así granjearle la felicidad terrena. Siglos y siglos de denostación de la sexualidad por parte de la Iglesia habían terminado, parafraseando a Thérèse, por envolver en un halo criminal todo lo relacionado con el placer sexual. Por ende, resultaba preciso, con el propósito de desembarazarse de los prejuicios que impedían gozar libremente de la sexualidad, demostrar, mediante argumentos, que la satisfacción de los instintos sexuales era tan natural como el acto de saciar la sed y el hambre, de manera que pretender impedirla no era a fin de cuentas sino un disparate. Todavía más, puesto que para reforzar la reivindicación emprendida el autor de Thérèse se sirvió de los conceptos utilizados por la Iglesia misma, si bien con fines por completo opuestos como veremos más adelante. Considero, además, que los argumentos de Thérèse, el abad T*** y el Conde son, a la larga, mucho más poderosos que las historias de clérigos corrompidos, ya que mientras éstas pueden ser estimadas como excepciones, la argumentación se dirige a la raíz misma del problema con el fin de desecar la fuente de la que manan los prejuicios. Así pues, formulado en su totalidad, el objetivo explícito de Thérèse es éste: reivindicar, más aún, legitimar la sexualidad con vistas a fomentar la felicidad personal así como el bien público.

A pesar de la falta de sistematicidad de los argumentos que aparecen a lo largo de la novela, trataré, en la medida de lo posible, de reunirlos en un conjunto coherente. Pues bien, la piedra de toque de todos los argumentos es Dios, cuya presencia, vale la pena resaltarlo, es aún incuestionable. No se trata, sin embargo, del Dios revelado de la Biblia o bien de cualquier otra religión, sino de aquel Dios fruto de la investigación acometida por la razón crítica. Sin embargo, tal y como le sucedió a Voltaire tras semejante examen, Dios quedó reducido apenas a un par de rasgos: un creador soberanamente bueno y perfecto, nos informa Thérèse hacia el final de la novela. Pero si Dios, de cuya bondad no puede dudarse, es el creador de nuestra organización ${ }^{3}$ (especie de disposición original de todas las partes y órganos de nuestro cuerpo que determina tanto nuestros gustos como nuestra forma de pensar) y por lo tanto de las pasiones que de ella resultan, de lo anterior se sigue, en primer lugar, que todas nuestras pasiones son igualmente buenas (o en todo caso igualmente naturales), así como que todas ellas

\footnotetext{
${ }^{3} \mathrm{O}$ si no Dios, sí la naturaleza, que a fin de cuentas no es, según argumenta el abbé T***, más que "un mot vide de sens" (88). Y aun en el caso de que existiera, ella no opera al margen de Dios, sino que es éste quien la dirige. De ahí que, concluye el abbé T***, "tout est Dieu, tout est bien" (89).
} 
son involuntarias, en segundo. Por lo demás, Dios no es sólo el creador de nuestra organización y con ella de nuestras pasiones, sino también quien nos pone en movimiento, de modo que si nuestra primera acción está determinada por nuestra disposición original (que es obra de Dios), de ello se sigue como consecuencia que el resto de ellas lo estará a su vez, convirtiendo así todos los actos de nuestra vida en una serie causal y necesaria en la que no se halla lugar alguno para la libertad. "Le coup de dés", dice el abad T***, "est le tableau de toutes les actions de notre vie. Un dé en pousse un autre auquel il imprime un mouvement nécessaire, et de mouvement en mouvement, il résulte physiquement un tel point. De même l'homme, par son premier mouvement, par sa première action, est déterminé invinciblement à une seconde, à une troisième, etc." (Boyer d'Argens, 2008: 110-111). ${ }^{4}$

Así pues, la legitimación de las pasiones ${ }^{5}$ culmina en un afianzamiento de la causalidad natural como el único principio determinante de nuestros actos, lo que significa que cada acción de nuestra vida tiene su causa en una acción precedente que es a su vez un efecto causado, y así sucesivamente hasta arribar a la causa incondicionada, esto es, al primer movimiento iniciado por Dios. De acuerdo con este argumento, el ser humano vendría a ser uno de esos automaton spirituale ${ }^{6}$ a los que alude Kant en una parte de la segunda crítica, y de cuya supuesta libertad se mofa al compararla con la de un asador automático, "el cual ejecuta también su movimiento por sí mismo, una vez que se ha activado su mecanismo" (Kant, 2000: (A 174) 230).

Apenas ahora comienza a entreverse que los argumentos filosóficos de Thérèse entrañan una concepción mecanicista del hombre, en la que éste termina por ser igualado a la máquina. Nada más natural, si se considera que la disposición de los órganos, el movimiento de los humores y la organización de nuestros cuerpos, en fin, el puro mecanismo, son las causas determinantes tanto de nuestros gustos más baladíes como de nuestros pensamientos más abstractos, limitando así a la razón a jugar un papel secundario en la determinación de la conducta. $Y$ es precisamente en este último punto, es decir, en las distintas maneras en las que conciben el concepto de razón, en donde estriba la diferencia más significativa entre la filosofía libertina y la ética kantiana; diferencia que, por cierto, se hace palmaria hacia el final del opúsculo de Kant titulado ¿Qué es Ilustración?, en donde afirma que el hombre, en virtud de su dignidad, es algo más que una máquina.

\footnotetext{
${ }^{4}$ A este tipo de causalidad Kant la llama causalidad natural.

${ }^{5}$ Lo que en Thérèse se llaman pasiones, en Kant se llaman inclinaciones. Es por ello que uso ambos términos indistintamente. Es importante notar que ambas son inspiradas por algún objeto sensible (de la experiencia).

${ }^{6}$ La noción de automaton spirituale proviene de Leibniz, y se opone a los automaton materiale en la medida en que los primeros tienen razón y los segundos no.
} 
Junto con la cancelación de la libertad propia de la filosofía libertina, viene aparejada una concepción de la razón como una capacidad que se reduce a, por un lado, hacernos conscientes de las pasiones y los pensamientos (ambos inevitables) que determinan a la voluntad, así como a explicar, o mejor aún, a legitimar, la existencia de ambos, por otro. Sin embargo, y en esto Thérèse, el abad $\mathrm{T}^{* * *}$ y el Conde se muestran definitivos, la razón no es capaz, según ellos, de determinar a la voluntad, y de ahí que, concluyen, dicha voluntad no sea libre. ${ }^{7}$ Para serlo, nos dice Thérèse en su Apostrophe aux téologiens sur la liberté de l'homme, el hombre tendría que ser capaz de determinarse a sí mismo, o dicho de otra manera, la razón tendría que ser capaz de determinar a la voluntad con independencia de las pasiones sensibles que su particular organización le impone; todavía más, continúa Thérèse un tanto enigmáticamente, si el hombre fuera libre, es decir, si poseyera una capacidad racional de acción, ello implicaría hacerlo igual a Dios. ¿Por qué? Thérèse no nos da la respuesta, y sin embargo, todo apunta a suponer que en la medida en que el hombre pudiera determinarse a sí mismo, ello lo convertiría en un ser puramente racional con capacidad para iniciar series causales a partir de la nada.

Kant, por el contrario, no duda al momento de asegurar que la razón posee dos usos diferentes: uno teórico y otro práctico. Es ésta, de hecho, una de sus mayores aportaciones a la filosofía moderna. De acuerdo con Kant, la misma razón no sólo posee un uso teórico, es decir, un uso que nos guía en el conocimiento de lo que es, sino también un uso práctico, cuya tarea es dictarnos qué debemos hacer, de tal suerte que ella funge como guía de la conducta. Dicho de otra manera, cuando hacemos un uso práctico de la razón nuestra meta reside no en conocer cómo es de hecho el mundo, sino en determinar lo que debemos hacer.

Por otro lado, Kant infiere la existencia del uso práctico de la razón apelando a las distintas clases de juicios que formulamos en el día a día. Cuando afirmamos, por ejemplo, que un acto debió o no debió suceder, no estamos, según Kant, haciendo un uso teórico de la razón, ya que para lo único que éste puede servirnos es para informarnos acerca de cómo es el mundo, de manera que, colige el filósofo, cuando pronunciamos juicios éticos, la razón se emplea de un modo distinto al especulativo, a saber, de un modo práctico. Pero si la razón goza de un uso parecido, si ella se arroga el derecho a enunciar juicios normativos, ello implica que los seres humanos pueden actuar, o al menos se representan que pueden hacerlo, merced a un tipo de causalidad distinta a la natural (la única capaz, según la filosofía libertina, de determinar nuestros actos), la cual

\footnotetext{
${ }^{7}$ Baste para prueba de ello el siguiente pasaje en el que la protagonista Thérèse interpela a los teólogos a propósito de la libertad que supuestamente ella tiene de escoger entre el amor a Dios y las pasiones sexuales: "Mais, répliquerez-vous, Dieu vous avait donné la raison pour vous éclairer. Oui, mais non pas pour me décider. La raison m'avait bien fait apercevoir les deux passions dont j'étais agitée [la función de hacernos conscientes], c'est par elle que j'ai conçu par la suite que, tenant tout de Dieu, je tenais de lui ces passions dans toute la force où elles étaient [función legitimadora]. Mais cette raison qui m'éclairait ne me décidait point" (17). Las cursivas son mías.
} 
no puede ser otra sino una causalidad por libertad, cuya condición de posibilidad descansa en la independencia de la voluntad respecto del tiempo. ${ }^{8}$ Según el ejemplo que da Kant en la solución a la tercera antinomia, ${ }^{9}$ a un ladrón no se le puede absolver de su robo aduciendo que estuvo determinado por algún antecedente biográfico o bien por cualquier otra circunstancia (como podría serlo la organización en sentido libertino), sino que suponemos, al contrario, que su robo no debió haber tenido lugar; suposición que encierra la idea de que el ladrón era capaz de actuar al margen de cualquier género de determinación sensible y por lo tanto temporal, en una palabra, que era libre. A la capacidad de iniciar una serie causal sin tomar en consideración ningún tipo de antecedente, Kant la llama libertad trascendental.

Una vez esbozadas las dos concepciones de la razón que subyacen a estas dos filosofías morales, pasemos a examinar más detenidamente los argumentos de ambas en lo que atañe a los fundamentos determinantes de la voluntad. Recordemos, con todo, que la reconstrucción de los razonamientos filosóficos ha de desembocar en un esclarecimiento de dos distintas nociones del ser humano, ambas igualmente representativas del siglo de la Ilustración.

Ya hemos visto que para la filosofía libertina exigirle a la razón que haga algo más que dilucidar cuáles son las pasiones que nos agitan excede todas sus posibilidades. En otros términos, la filosofía libertina niega la existencia de un uso práctico de la razón. De acuerdo con lo defendido por Thérèse en su Apostrophe aux téologiens sur la liberté de l'homme, la determinación de la voluntad es producto de un esclarecimiento en el que la razón nos hace conscientes de las ganas que tenemos de hacer o de evitar una acción, así como del placer o del disgusto previstos como consecuencia de ella. No obstante, dice Thérèse, "cette volonté et cette détermination sont aussi parfaitement soumises aux degrés de passion ou de désir qui nous agitent qu'un poids de quatre livres détermine nécessairement le côté d'une balance qui n'a que deux livres à soulever dans son autre bassin" (Boyer d'Argens, 2008: 18-19). Lo anterior nos remite de nuevo al ya mencionado automaton spirituale, cuyas pasiones, a diferencia de las del automaton materiale, pasan por el filtro de la razón, mas sin que ésta tenga la más mínima injerencia al momento de determinar a la voluntad. ${ }^{10}$

\footnotetext{
${ }^{8}$ De acuerdo con Kant, lo único que su sensibilidad le da conocer al hombre son fenómenos. Los fenómenos conforman toda su experiencia sensible. Ahora bien, todos los fenómenos acaecen en el tiempo. Al ser éste una sucesión de momentos, cada suceso que pasa en él tiene su causa en uno anterior, y éste a su vez en otro precedente y así sucesivamente. La ley de la causalidad natural es, pues, la que rige la relación de los fenómenos entre sí. Ahora se entiende por qué, si ha de haber una causalidad libre, la voluntad debe ser independiente respecto del tiempo. Semejante independencia, que coloca a la voluntad al margen de cualquier determinante sensible (fenoménico), representa la faceta negativa de la libertad.

${ }^{9}$ Cf. Immanuel Kant, Crítica de la razón pura. Trad. Pedro Ribas. Madrid, Alfaguara, 1998, A554, B582/ A555, B583.

${ }^{10}$ En el escolio I al segundo teorema de la Crítica de la razón práctica, Kant indica que poco importa de dónde provengan nuestras representaciones (sea de la sensibilidad o del entendimiento), siempre y cuando sean ellas, y no la razón, las que determinen a la voluntad, ya que en ese caso estaríamos tan sometidos a la causalidad natural como los animales.
} 
Así pues, el grado en el que las pasiones nos enardecen nos impele inevitablemente a hacer algo. Pasiones que, como ya hemos visto, son por completo involuntarias en la medida en que responden a nuestra organización, la cual, sin embargo, no se mantiene idéntica en el transcurso de la existencia sino que está sujeta a los cambios que puedan sobrevenirle durante ésta. De ahí que, argumentan los personajes de la novela, no sólo sea nuestra organización, sino también las sensaciones que la modifican, las que determinan a la voluntad a actuar. En todo caso, para la filosofía libertina el ser humano no deja de ser una máquina que, parecida a una veleta, hoy desea una cosa para mañana desear otra, a pesar de lo cual no debe sentirse culpable al momento de perseguir los fines a los que sus pasiones le arrastran, pues como asevera esa misma filosofía "tout est Dieu", de lo cual se sigue que "tout est bien"."

En última instancia, la tesis de que actuamos únicamente a partir de incentivos sensibles a los que resulta inútil oponernos termina en una conclusión que, para escándalo de Kant, cancela a la moralidad, a saber: que el único principio determinante de todas las acciones de nuestra vida es el amor propio, es decir, la búsqueda del bienestar personal, del placer, en fin, de la felicidad. ${ }^{12}$ Sin embargo, si el único principio que guiara la conducta fuera ése, piensa Kant, el hombre no se diferenciaría esencialmente de ningún otro objeto y criatura del mundo, pues al igual que ellos, estaría subyugado por la causalidad natural.

Para Kant, por el contrario, la voluntad es razón práctica, ${ }^{13}$ lo cual significa que ella se determina en todo momento con independencia de las inclinaciones (libertad negativa). En otras palabras, de acuerdo con la ética kantiana la voluntad es noumenal, lo que implica que se halla fuera del tiempo, y por lo tanto fuera de la serie causal que encadena de manera necesaria un fenómeno con otro (serie que, por cierto, es la que reivindica el abbé $\mathrm{T}^{* * *}$ con su metáfora de los dados). ${ }^{14}$ Un ejemplo puede aquí aclarar el panorama. Supongamos que padezco una inclinación "irrefrenable" a beber vino. Cuando ella se haga sentir, parecería imposible, y así argumentaría Thérèse, contar con la opción de decidir entre beber o no beber; y sin embargo, objetaría Kant, no es la inclinación sino la razón la que resuelve si vale la pena o no hacerlo. Así, Kant no niega, y en esto coincide con los filósofos libertinos, que exista en nosotros una parte pasiva que se confine a padecer inclinaciones involuntarias. Lo que sí niega, y en este punto se desmarca de aquéllos, es que sean esas mismas inclinaciones las que

\footnotetext{
${ }^{11}$ Aventura la filosofía libertina que incluso las pasiones que nos llevan al crimen no son malas en sí mismas (pues provienen de Dios), sino tan sólo en relación con el bien público y el orden establecido.

${ }^{12}$ Kant parte del supuesto de que si hay moralidad, ella debe ser categórica, es decir, su principio debe ser una ley. El principio del amor propio, sin embargo, depende de la experiencia y por lo tanto es contingente. El principio de la moralidad, pues, debe encontrarse fuera de la experiencia.

${ }^{13}$ Cf. Fundamentación para una metafisica de las costumbres, A36\A37.

${ }^{14} \mathrm{Si}$ la razón práctica decide actuar siguiendo alguna inclinación (ocasionada por la representación placentera de un objeto sensible), ello significa que ella coloca el fundamento determinante de la voluntad en un fenómeno, y por lo tanto en la ley de la causalidad natural, que es la que rige la relación de los fenómenos entre sí.
} 
determinen a la voluntad, hurtándole por ese medio a la razón la prerrogativa de decidir qué inclinaciones merecen ser realizadas y cuáles no.

Hasta aquí con la faceta negativa de la libertad. Existe, sin embargo, su faceta positiva. De acuerdo con Kant, la voluntad es un tipo de causalidad; no cualquiera, sino una por libertad. Ahora bien, el hecho de ser libre no la exime de tener una ley, pues "el concepto de una causalidad conlleva el de leyes según las cuales mediante algo que llamamos causa ha de ser puesta otra cosa, a saber, la consecuencia" (Kant, 2012: (A97/ A98) 166-167). Así pues, a pesar de ser libre en sentido negativo, la voluntad no es anómica. Pero su ley, con todo, se distingue de la ley rectora de los fenómenos, esto es, de la causalidad natural. Por lo tanto, concluye Kant, semejante ley ha de tener un origen racional, y en virtud de ello la razón ha de ser capaz de dársela a sí misma con independencia de cualquier incentivo sensible. Dicha ley no es otra, por supuesto, que el principio supremo de la moralidad: el imperativo categórico. En tanto sea éste y no el amor propio el principio que funja como fundamento determinante de la voluntad, el ser racional tiene derecho a tenerse por libre en sentido trascendental, es decir, tiene derecho a suponer que él ha iniciado una serie causal libre de la sujeción temporal. Por lo demás, era justamente ese género de libertad el que los filósofos libertinos se esforzaron por suprimir: Thérèse al alegar que su aceptación haría del hombre un Dios, el abbé $\mathrm{T}^{* * *}$ al argüir que ella traería consigo la suposición, para él absurda, de que "le néant produit un effet" (Boyer d'Argens, 2008: 111).

Finalmente, y con el propósito de sortear los malentendidos que pudieran desprenderse de la explicación anterior, me gustaría clarificar algunas ideas. Ya hemos visto que, para Kant, toda voluntad es libre en sentido negativo. En cambio, no toda voluntad lo es en sentido positivo, pues para ello resulta preciso que se otorgue una ley racional que la determine. Sin embargo, cuando la razón decide ser la esclava de las pasiones, la "voluntad no se da una ley a sí misma, sino tan sólo la prescripción de acatar racionalmente leyes patológicas" (Kant, 2000: (A 59) 121), o lo que es lo mismo, la prescripción racional de someterse a la causalidad natural. No obstante, de lo anterior no hace falta concluir la aversión de Kant por las acciones determinadas por incentivos sensibles. Kant estaba consciente de que no sólo somos seres racionales, sino también seres sensibles que precisamos, para sobrevivir, de acatar racionalmente ciertas inclinaciones. Antes que rebajar a los sentidos, su intención consistía, más bien, en arrebatarle a la razón sometida voluntariamente a las inclinaciones, el supuesto privilegio de ser el único fundamento determinante de la voluntad, para de esa forma demostrar que la moralidad no era un vano fantasma de la razón.

\section{$I V$}

Si bien uno puede discutir los argumentos filosóficos sin tomar en consideración nada ajeno a los mismos, lo cierto es que dicha perspectiva soslaya el significado que ellos pueden tener desde un punto de vista histórico. Analizar la filosofía libertina y la kan- 
tiana al margen de cualquier otra consideración a excepción de la filosofía misma es válido, pero implica perder de vista la singularidad de ambas, pues se olvida el contexto en el que surgieron, así como sus posibles consecuencias en el ámbito de la historia de las ideas.

Para el autor de Thérèse, la bondad de las pasiones y la negación de la libertad son indisolubles del anhelo por emancipar a sus coetáneos del lastre del pecado original. Si la naturaleza (de donde suponían los teólogos que provenía todo mal) no es sino "una palabra vacía de sentido", o en todo caso un ente que opera a través de las órdenes de un Dios bondadoso, entonces no hay motivo para ruborizarse al momento de satisfacer esas mismas pasiones que él, creador de todo lo existente, ha puesto en nosotros. Es curioso, y sin embargo, la filosofia libertina invierte la famosa frase de Dostoievski, pues en este caso, si hay Dios, todo está permitido. ${ }^{15}$ Más todavía, pues dichas inclinaciones determinan necesariamente todos los actos de nuestra vida, dando así la impresión de que para reivindicar a la felicidad se debiera abdicar de la moralidad, o al menos de uno de sus conceptos básicos: la libertad. Pero éste es, creo, el objetivo último de Thérèse: negar la moralidad. No basta, en efecto, con justificar el carácter bondadoso de las pasiones, sino que resulta indispensable, además, anular la libertad. ¿Por qué? Pues porque como dice Kant en un pasaje de la Fundamentación, aceptar que la razón goza de un uso práctico implica aceptar de manera implícita que la felicidad debe posponerse a un objetivo más importante: la moralidad. La filosofía libertina hace gala así de esa suerte de misología u odio hacia la razón de la que habla Kant en ese mismo pasaje, y que evidencia que en orden a legitimar del todo a las pasiones y por lo tanto a la felicidad, debe renunciarse al uso práctico de la razón y en última instancia a la moralidad.

¡Llegó el tiempo de disfrutar, de ser felices aquí y ahora! ¡El hombre es inocente!, ¡El hombre es un ser nacido para el placer!, ¡El hombre es una máquina!, claman jubilosamente los personajes de Thérèse con un profundo y ebrio sentimiento de alivio. Una máquina, un automaton spirituale, un animal con razón, un ser heterónomo, un ser obligado a entrar en razón por medio de castigos: he ahí el ser humano según la filosofía libertina.

Y mientras tanto, aún resuena, adusta, la frase de Kant: el hombre, en virtud de su dignidad, es algo más que una máquina. Pero, ¿en qué consiste semejante dignidad? En su calidad de ser un fin en sí mismo. Si la voluntad, en tanto noúmeno, se halla fuera del tiempo y por lo mismo libre del influjo de la causalidad natural, entonces es ella quien decide qué inclinaciones, de entre todas las que padece, tienen valor y cuáles no. A esta capacidad racional de los seres humanos de ser fuente de valor Kant la denomina "humanidad", y es en virtud de ella que el hombre, como por lo demás cualquier otro ente racional, adquiere su dignidad en tanto fin en sí mismo. El hombre es, pues, el único ser sobre la tierra que, según Kant, posee valor intrínseco en la medida en que en él radica el valor de todo lo demás. Sin su presencia, nada tiene importancia

\footnotetext{
${ }^{15}$ Es sólo en relación al bien público (de origen humano) que hay pasiones malas, como matar o enriquecerse ilícitamente. Pero desde un punto de vista absoluto, "tout est Dieu, tout est bien".
} 
ni mucho menos sentido, pues es él quien, merced a su interés por ellas, vuelve a las cosas valiosas.

Sin embargo, existe aún un estadio ulterior a la humanidad: la personalidad. Quien se entrega racionalmente al dominio de la causalidad natural, opta por la heteronomía de la máquina, del animal, del autómata. Quien se rija, en cambio, por el imperativo categórico, cambia la heteronomía por la autonomía en tanto se da una ley a sí mismo, en tanto no es su voluntad la que se halla sometida a la naturaleza, sino la naturaleza a su voluntad. Así, tras haber caído dos veces de la cima de la creación, una a causa del heliocentrismo, otra a causa del mecanicismo, Kant coloca de nuevo al hombre en su cúspide al convertirlo en el único ser autónomo sobre la tierra. He ahí su dignidad, he ahí el fin de su vida: no ser feliz, sino ser moral.

\section{Obras citadas}

Argens, Boyer de. 2008. Thérèse Philosophe. París: Actes du Sud.

KANT, Immanuel. 2012. Fundamentación para una metafísica de las costumbres.

Trad. Roberto Rodríguez ARAmAYo. Madrid: Alianza. 2000. Crítica de la razón práctica. Trad. Roberto RODRÍGUEZ ARAMAYO. Madrid: Alianza.

1998. Crítica de la razón pura. Trad. Pedro RIBAS. Madrid: Alfaguara. 